Instructions for authors, subscriptions and further details:

http://brac.hipatiapress.com

\title{
Hogares: Duelos y Naufragios. Lugares de Perturbación e Inquietud en la Creación Artística Actual
}

Purificación Mayobre Rodríguez

1) Universidad de Vigo (España)

Date of publication: February $3^{\text {rd }}, 2016$

Edition period: February 2016 - June 2016

To cite this article: Mayobre Rodríguez, P. (2015). Hogares: duelos y naufragios. Lugares de perturbación e inquietud en la creación artística actual. Pontevedra: Diputación de Pontevedra. [Review of the book]. Barcelona, Research, Art, Creation, 4(1), 102-113. doi: 10.17583/ brac. 2016.1850

To link this article: http://dx.doi.org/10.17583/brac.2016.1850

\section{PLEASE SCROLL DOWN FOR ARTICLE}

The terms and conditions of use, except where otherwise noted, are related to the Open Journal System and to Creative Commons Attribution License (CCBY). The indication must be expressly stated when necessary. 
BRAC - Barcelona Research Art Creation. Vol. 4 No. 1, February 2016, pp. 102-113

\section{Reviews (I)}

Herranz Pascual, Y., Gil Rodríguez, A. (2014). Hogares: duelos y naufragios. Lugares de perturbación e inquietud en la creación artística actual. Pontevedra: Diputación de Pontevedra.

ISBN: 978-84-8457-417-7. Depósito Legal: PO 392-2014

Los estudios de género computan en su haber un amplio campo teórico, explicado desde diversas disciplinas, desempeñando la creación artística un lugar muy destacado por la capacidad que tiene de representar o expresar la idea, el concepto o la subjetividad de sus artífices, pero también porque las obras artísticas no se limitan a reflejar la realidad, sino que al tiempo que la presentan y representan, en esa misma medida, la interpretan, organizan, legitiman y generan.

El libro publicado por Yolanda Herranz Pascual y Ana Gil Rodríguez con el título Hogares: Duelos y Naufragios. Lugares de Perturbación e Inquietud en la Creación Artística Actual, publicado por la Diputación de Pontevedra, siguiendo la línea iniciada por autoras como Virginia Woolf en el ámbito de la literatura o Louise Bourgeois en el mundo del arte, está dedicado a problematizar la representación del hogar en la civilización occidental como un espacio de paz, felicidad, protección y sosiego. Ideal expresado habitualmente en la frase "Hogar, dulce hogar" y en el arquetipo de mujer como "ángel del hogar" que debe asumir que su lugar en el mundo se halla en el ámbito doméstico, dejando la esfera pública para el dominio del varón.

El primer capítulo, que tiene el título de Reflexiones en torno al hogar, se inicia con una clarificación conceptual de los conceptos de casa, hogar,

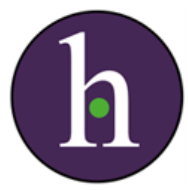


familia y lo doméstico. A continuación se analizan las causas de la escisión del espacio público y privado y de la asignación de roles sociales en función del sexo en dichas esferas, explicando las autoras que apelar a la naturaleza o a la biología para justificar la ocupación de esos ámbitos es una falacia, pues los sistemas sexo/género son una representación cultural que responden a relaciones históricas y sociales de poder y control.

Un estudio más minucioso del espacio doméstico como lugar de opresión, que reproduce situaciones de dominación que funcionan como espejo de las relaciones patriarcales existentes en la sociedad, se presenta en el segundo capítulo, El hogar como exilio latente, en el que a partir del valor simbólico de las diferentes estancias de la vivienda, de su asociación con deseos y temores inconscientes, y de la metáfora del ángel exiliado en el hogar se desvela la cara oculta de la morada familiar, el envés de aquello que antaño en el domicilio resultaba hospitalario, íntimo, placentero: lo siniestro. En el recorrido por los diversos habitáculos de la casa observamos la irrupción de lo siniestro: el vestíbulo, los pasillos, la cocina, el salón, el baño o el dormitorio pasan de ser un lugar confortable, familiar y seguro a convertirse en algo extraño e inhóspito. Particularmente ominoso resulta el dormitorio, que de ser un espacio de sueños, descanso o placer, puede convertirse en un campo de batalla, un cuarto de agresión, violencia sexual y muerte.

En el tercer y último capítulo, El espacio doméstico del desasosiego en la creación artística contemporánea, se presentan obras de artistas que han escenificado la casa como lugar de inquietud, como escenario de amor y odio o como espacio de dominio y control. Entre las creaciones elegidas para expresar esa desazón quisiera resaltar el carácter inquietante encarnado en la obra de Gino Rubert, Héroes, cuyos personajes no se sabe si se aman o se odian. No menos escalofriante o perturbadora resulta la pintura de Paula Rego por las historias o figuras extrañas que personifica en el salón de su casa. Por último, no podía faltar en esta galería de producciones seleccionadas, la obra de Frida Kahlo en la que la habitación y la cama ocupan un lugar tan destacado. Unos cuantos piquetitos significa el espacio doméstico y, más en concreto, la alcoba o la cama como un lugar de tormento y muerte.

En síntesis, el libro que comentamos pone en evidencia que la perspectiva de género aplicada a las creaciones artísticas permite romper con la tradición, zarandear los modos convencionales y la violencia simbólica que supone la "naturalización" y la "universalización" del canon masculino, pero también fomenta la expresión en las obras artísticas de un contradiscurso que subvierte el ideal de domesticidad legitimado por un rígido sistema patriarcal de valores 
orientados a la sumisión y mitificación de las mujeres, al tiempo que permite denunciar la crudeza y el drama que puede encerrar el "hogar, dulce hogar".

Purificación Mayobre Profesora Titular de Filosofía, Universidad de Vigo. (España) Miembro activo desde su fundación, en el año 2000, de la Cátedra Caixanova de Estudios Feministas

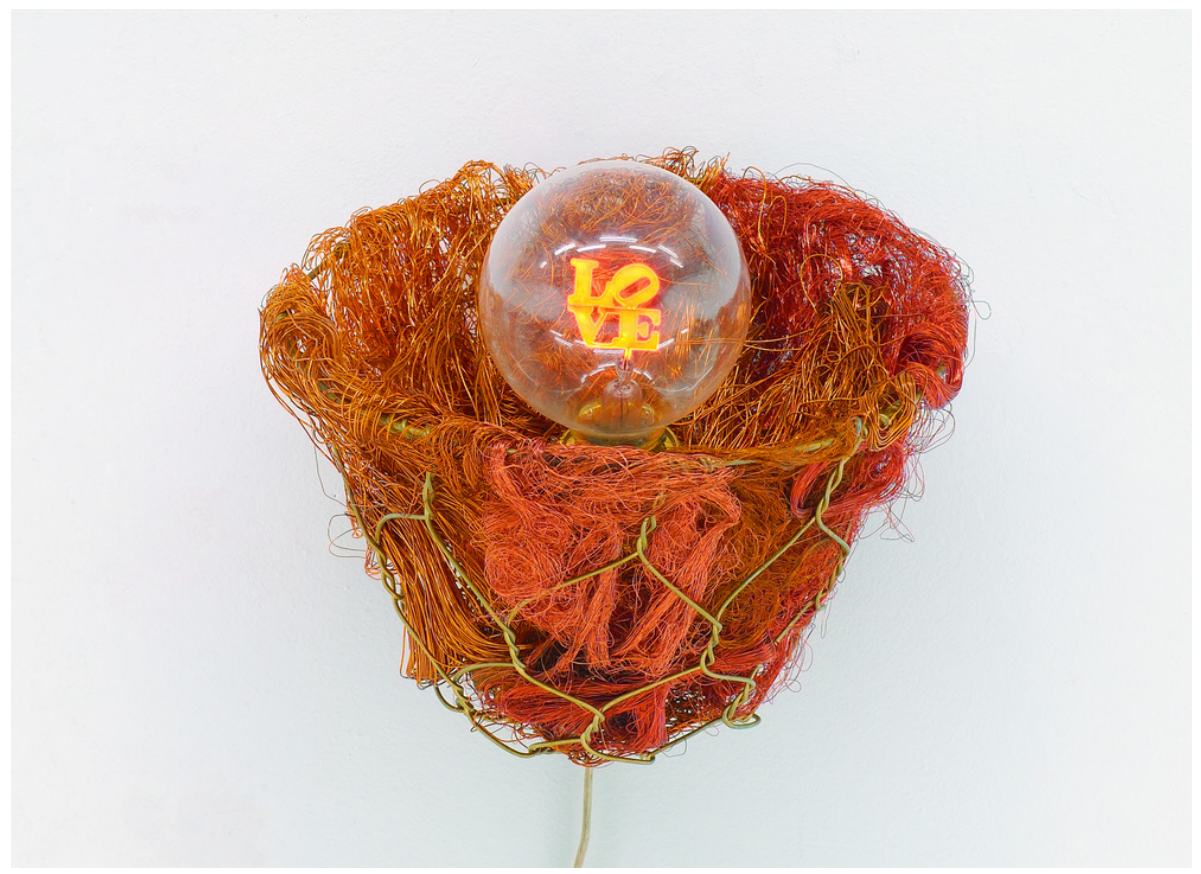

Figura 1. Nido de amor (1989), Yolanda Herranz. Texto, hierro, hilo de cobre y luz. $30 \times 20 \times 20 \mathrm{~cm}$ 


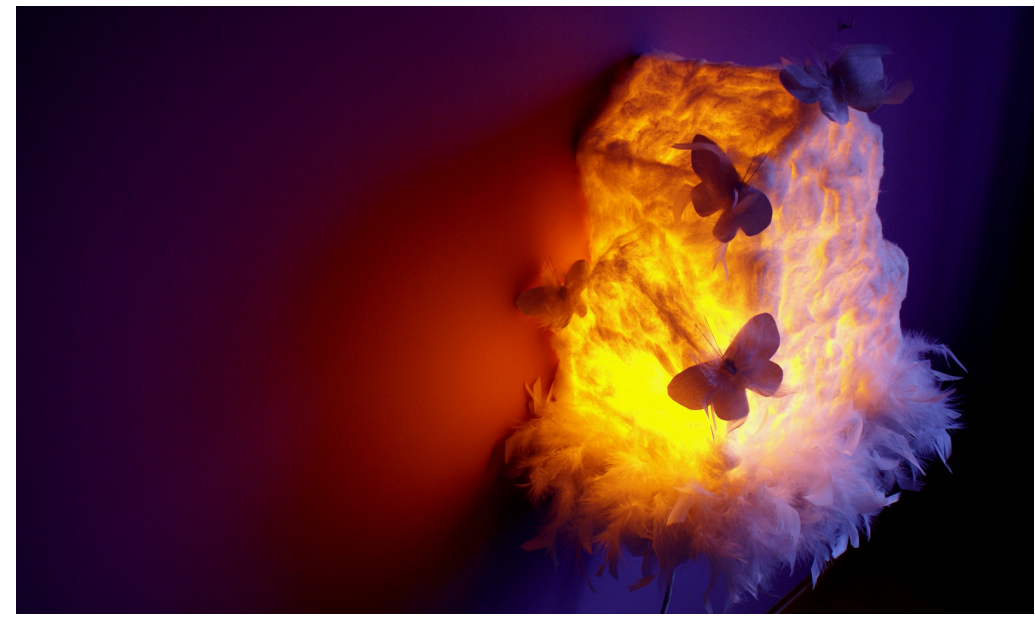

Figura 2. Hogar, dulce Hogar I, (2009). Ana Gil. Alambre, algodón, papel, madera, plumas, imán, focos rotativos de emergencia, alimentador de corriente. 41 x 45 x 58 $\mathrm{cm}$

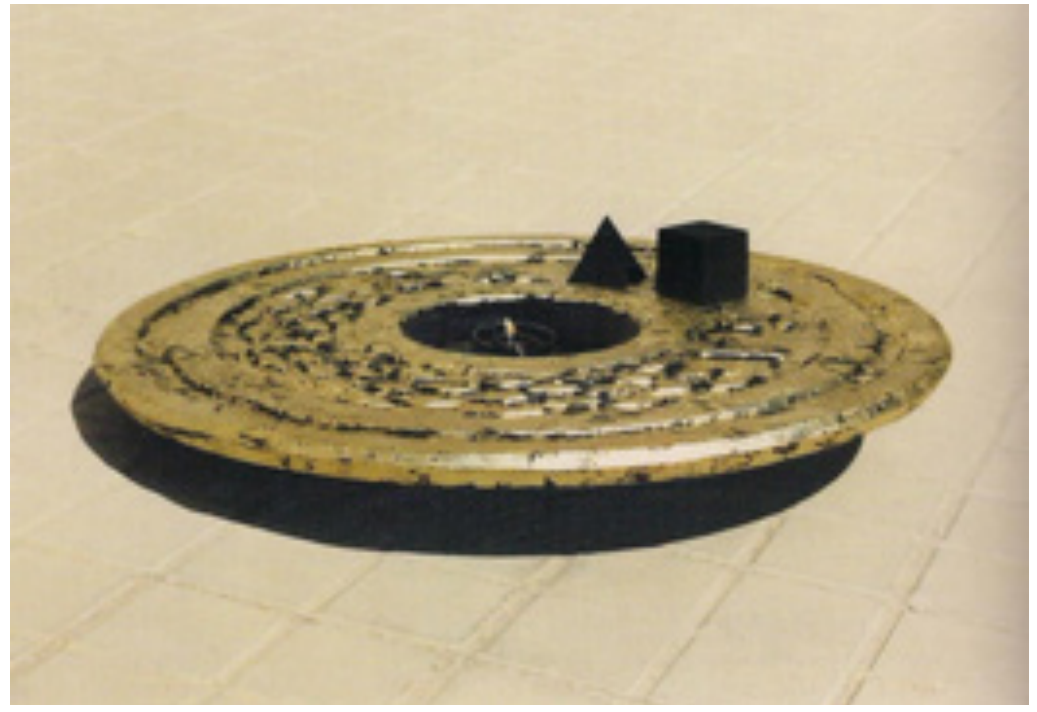

Figura 3. Casa (1989). Yolanda Herranz. Texto, hierro, oro, madera, aceite y luz. $20 \times 80 \times 80 \mathrm{~cm}$ 

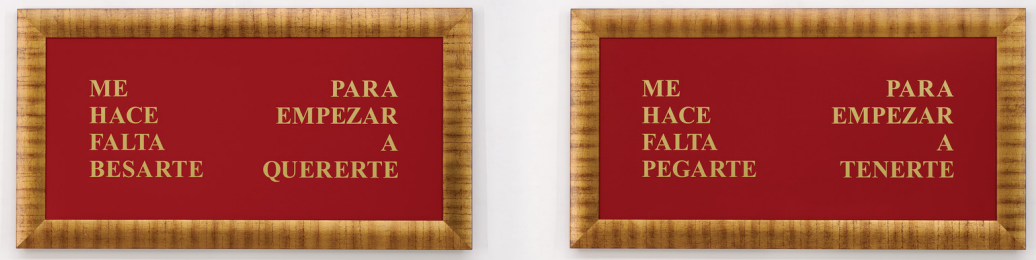

Figura 4. Me hace falta besarte para empezar a quererte, Me hace falta pegarte para empezar a tenerte (2007). Yolanda Herranz. Texto, madera y serigrafía oro sobre aluminio lacado rojo sangre. $74 \times 320 \times 3 \mathrm{~cm}$

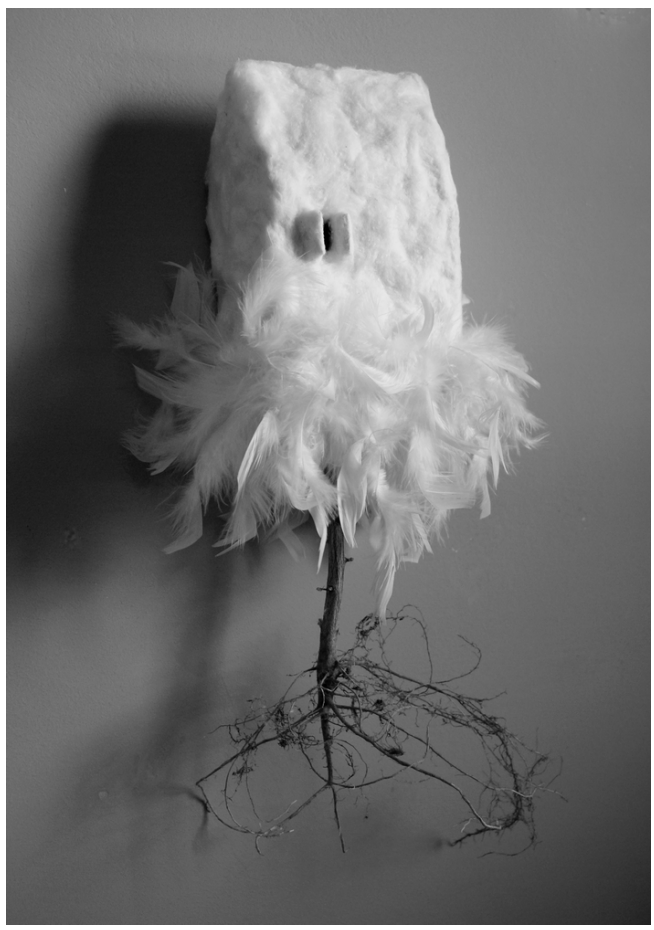

Figura 5. La casa de los ausentes (2011). Ana Gil. Cartón, algodón, pluma, plástico, papel y raíces. Instalación 


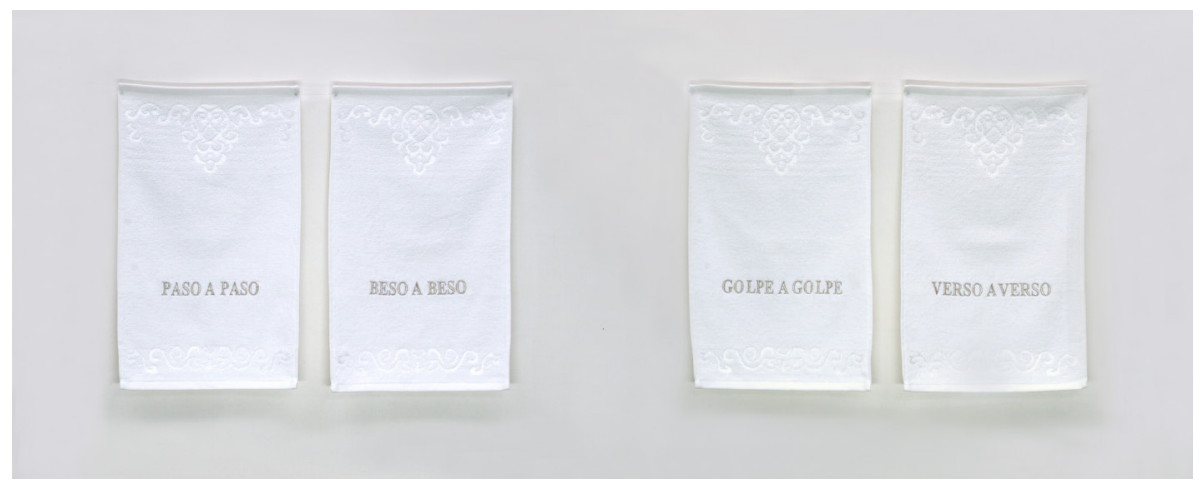

Figura 6. Paso a Paso Beso a Beso Golpe a Golpe Verso a Verso (2008). Yolanda Herranz. Texto y toallas de mano bordadas. Conjunto de 4 piezas: $50 \times 180 \times 2 \mathrm{~cm}$

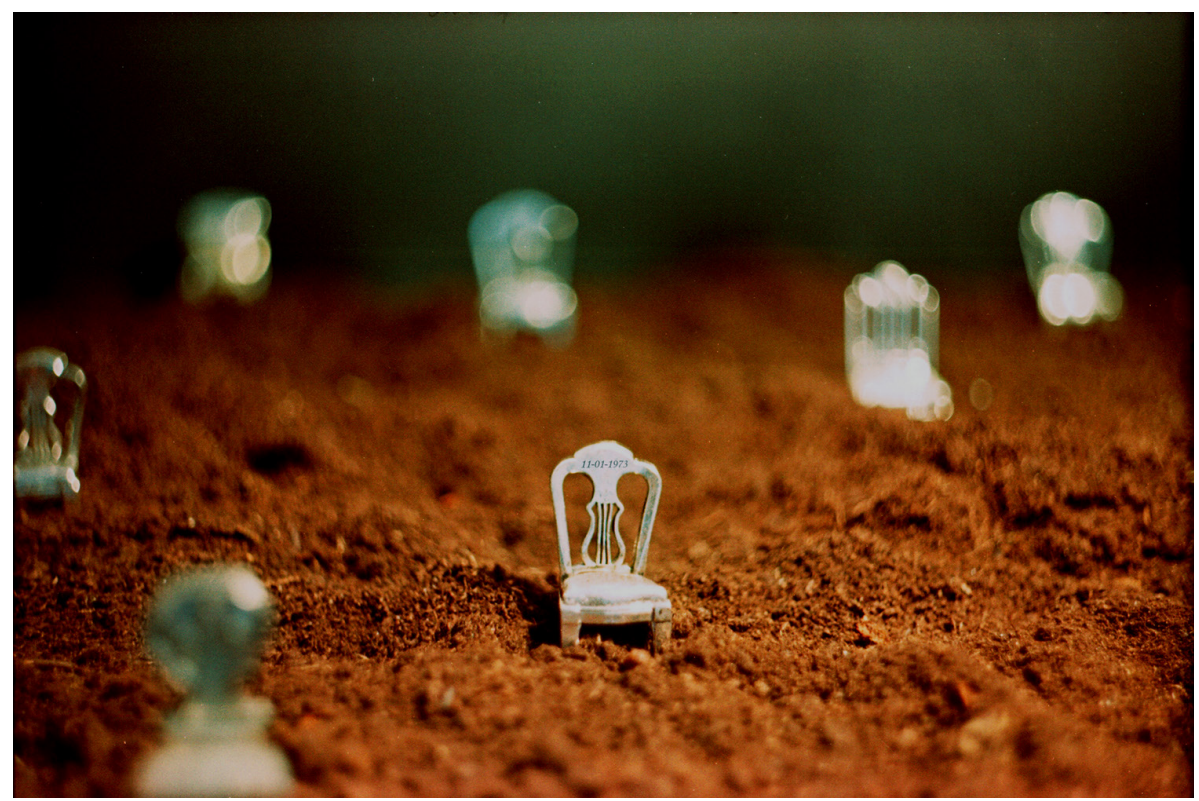

Figura 7. Residuos (2005). Ana Gil. Sillas metálicas, texto, tierra y texto. Maqueta de instalación 

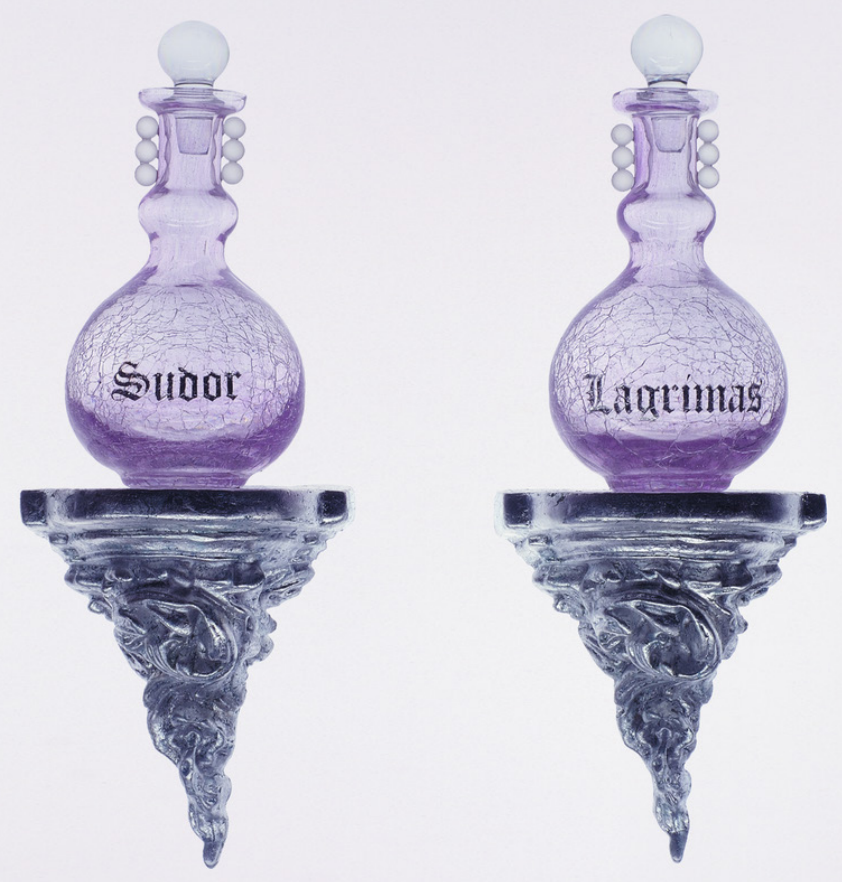

Figura 8. Sudor y lágrimas (2003). Yolanda Herranz. Texto, cristal, poliéster, pintura y plata. $36 \times 44 \times 10 \mathrm{~cm}$ 


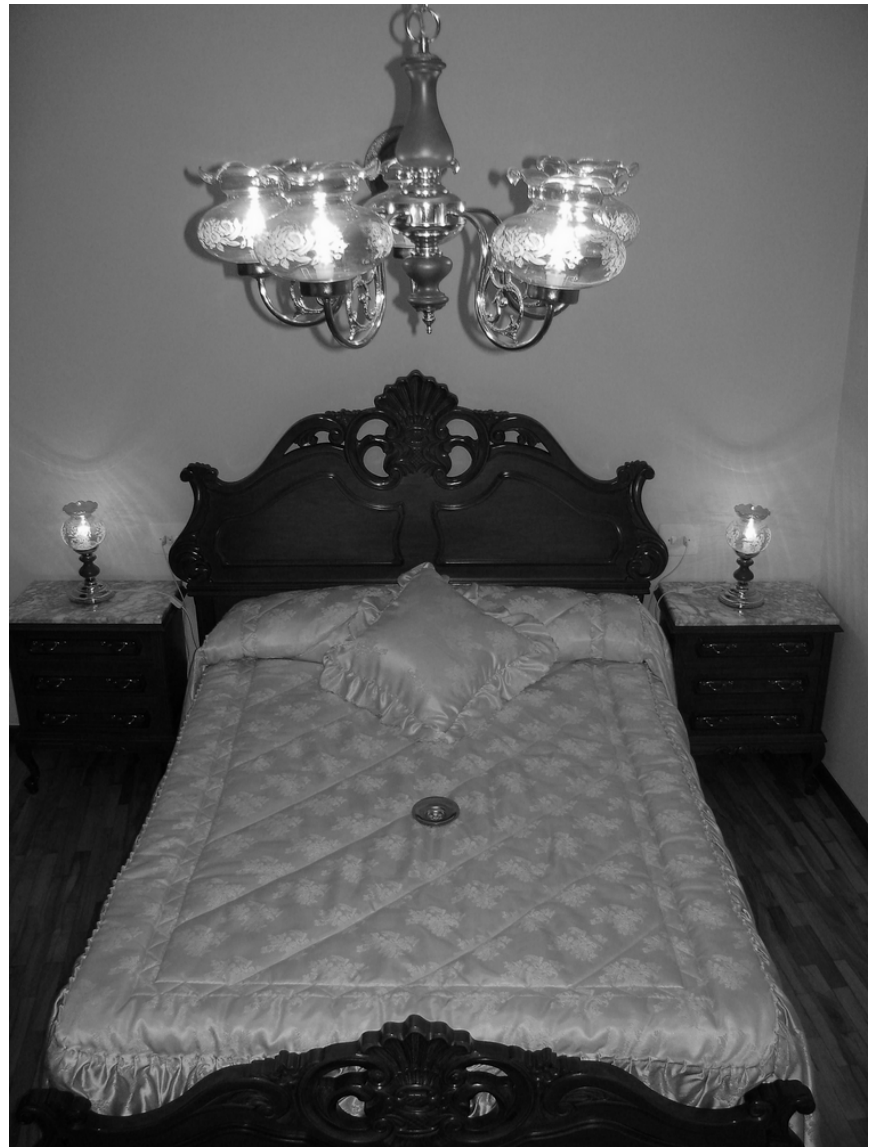

Figura 9. Sumideros II (2004). Ana Gil. Cama y sumidero de acero. Intervención 


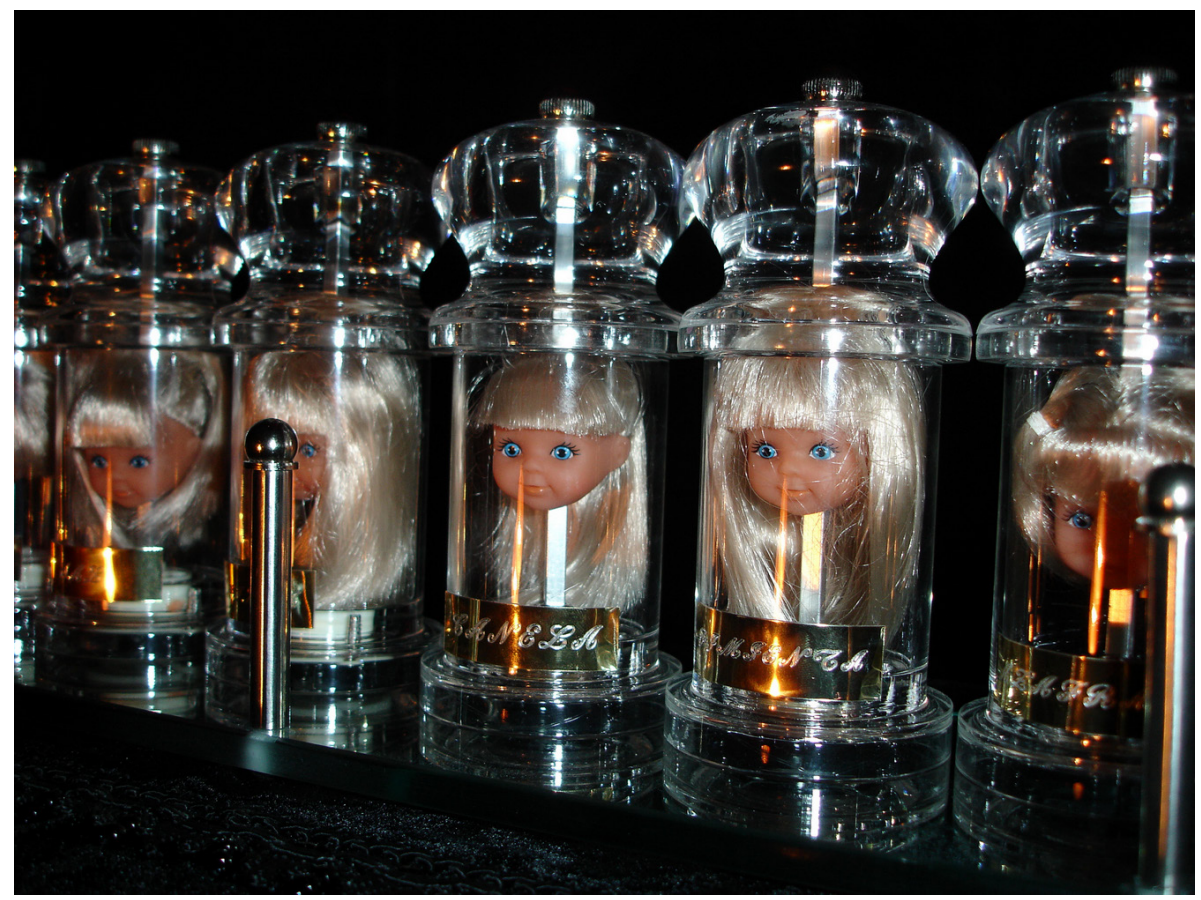

Figura 10. Condimentos (2006). Ana Gil. Hierro, plástico, aluminio, terciopelo, encaje y abalorios. 100 x 48 x $39 \mathrm{~cm}$ 


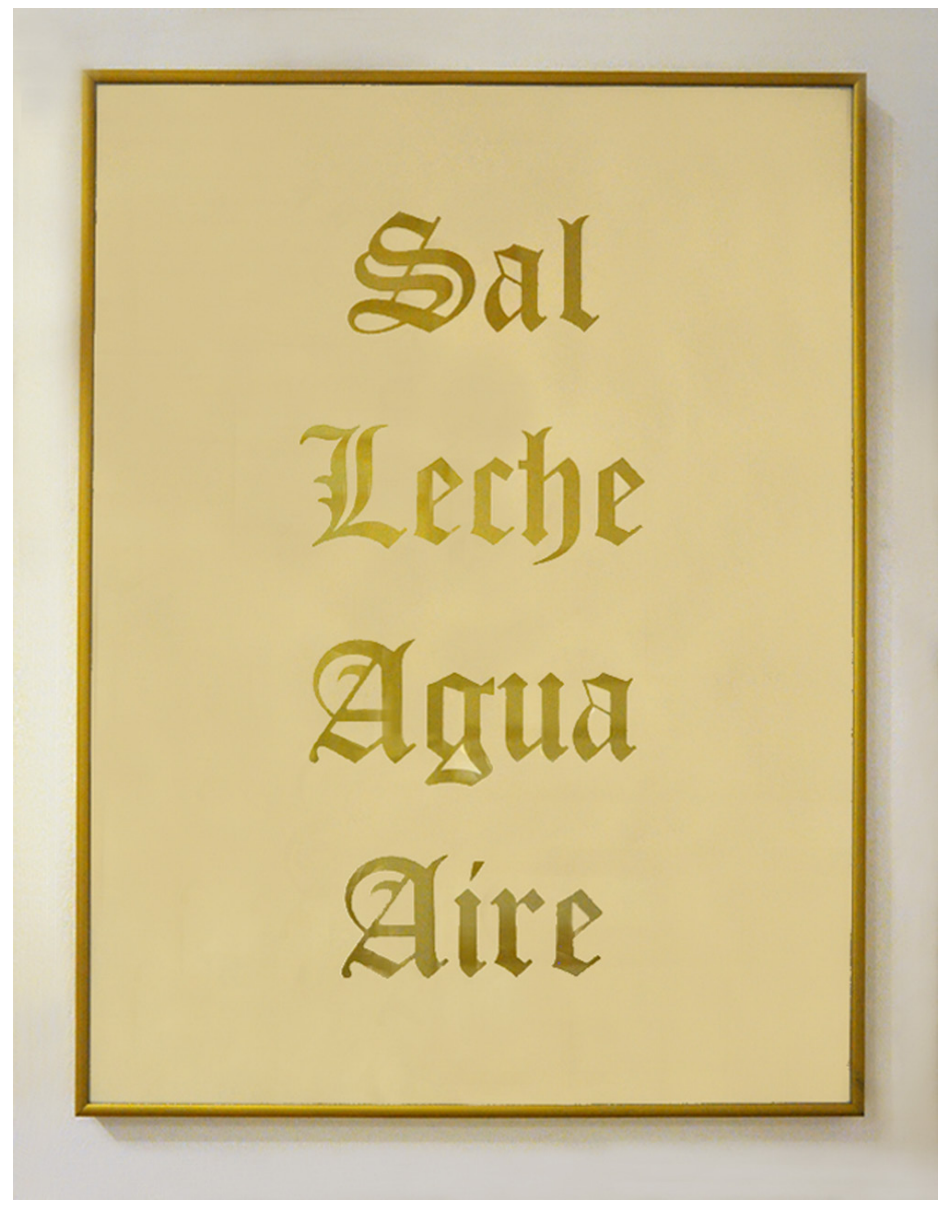

Figura 11. Sal Leche Agua Aire (oro II). Serie: "Fluidos, secreciones y excrementos de mi cuerpo" (2010). Yolanda Herranz. Texto y serigrafía oro sobre papel irisado dorado y aluminio anonizado oro. $61,5 \times 46,5 \times 2 \mathrm{~cm}$ 


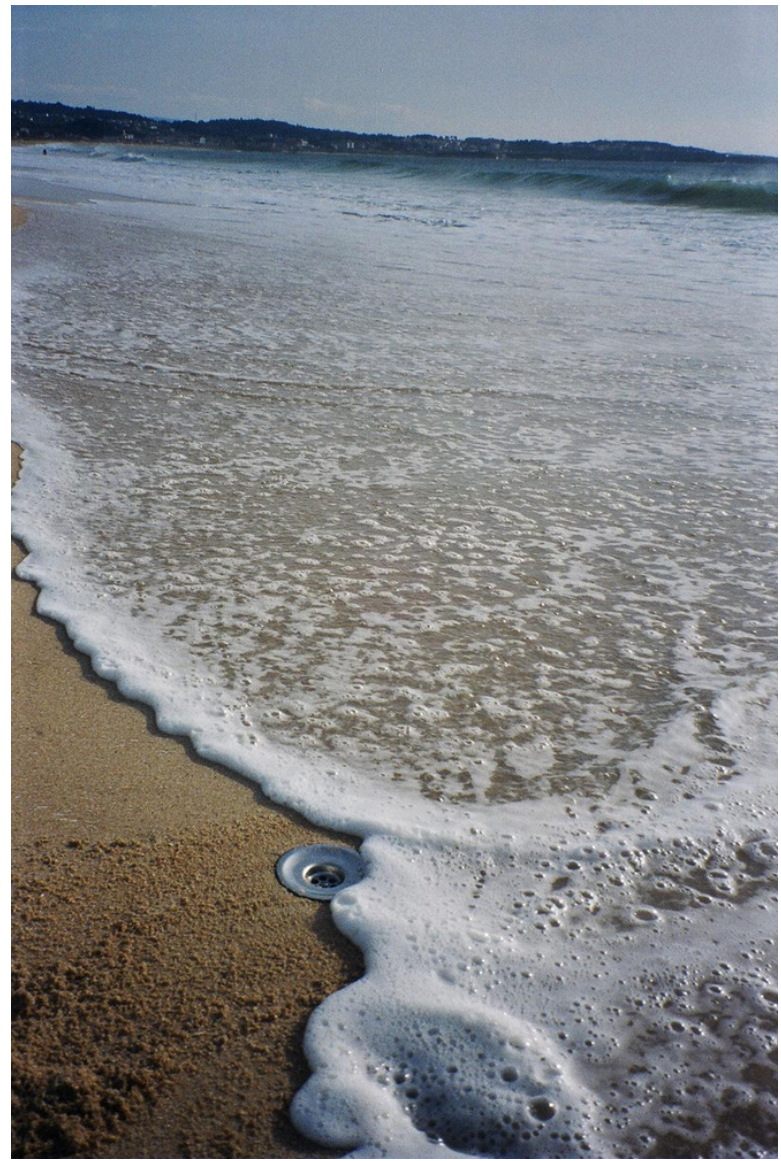

Figura 12. Sumideros I (2004). Ana Gil. Sumidero de acero inoxidable. Intervención en la ría de Arousa, Pontevedra 
Figura 13. Nido de amor (1989). Yolanda Herranz. Hierro y algodón. 20 x 20 x $30 \mathrm{~cm}$ 